\title{
THE ROLE OF SYNOVECTOMY IN TOTAL KNEE ARTHROPLASTY: A PROSPECTIVE ANALYSIS OF 30 CASES
}

\author{
Mohammed Ashraf M11, Kumar Chandan², Sumesh Shanker V3, Sukesh A. N4 \\ 1 Professor and HOD, Department of Orthopaedics, Government TD Medical College, Alleppey, Kerala, India. \\ ${ }^{2}$ Senior Resident, Department of Orthopaedics, Government TD Medical College, Alleppey, Kerala, India. \\ 3Senior Resident, Department of Orthopaedics, Government TD Medical College, Alleppey, Kerala, India. \\ 4Junior Resident, Department of Orthopaedics, Government TD Medical College, Alleppey, Kerala, India.
}

\section{ABSTRACT}

\begin{abstract}
AIM AND OBJECTIVES
Aim and objective of this study is to assess role of synovectomy during TKR on joint effusion, haemarthrosis, patellar clunk, recurrent synovitis, and histopathological diagnosis in patients undergoing Total Knee Arthroplasty (TKA).
\end{abstract}

\section{MATERIAL AND METHODS}

We studied prospectively 30 patients with osteoarthritis of knee treated with total knee arthroplasty with near-total synovectomy. Patients were in the age group 55-70 years. The overall efficacy of both procedures was assessed postoperatively by determination of blood loss from the drain, pain, and Lysholm knee functional score.

\section{RESULTS}

All 30 patients have been followed up for an average of 3 years for assessment for postoperative pain, knee joint effusion, patellar clunk, range of movement, and stability of prosthesis. During the postoperative 48 hours, the mean blood loss was slightly higher. To conclude, supplementing near-total synovectomy along with TKA may provide complete pathological diagnosis, beneficial in inflammatory arthritis, and some special synovial pathology like pigmented villonodular synovitis, rheumatoid arthritis, tuberculous arthritis, and haemophilic arthritis. Better long-term pain relief and functional outcome due to the removal of pathological synovium have been observed after synovectomy along with total knee arthroplasty.

\section{CONCLUSION}

Performing synovectomy in TKA will give complete pathological diagnosis, avoiding persistence of synovial pathology along with long-term benefits of synovectomy in the form of minimal to no joint effusion, less pain, absence of synovial hypertrophy, patellar clunk, and good range of movement of knee.

\section{KEYWORDS}

Osteoarthritis (OA), Total Knee Arthroplasty (TKA), Synovectomy, PVNS, RA, Tuberculous Arthritis Knee.

HOW TO CITE THIS ARTICLE: Ashraf MM, Chandan K, Shanker SV, et al. The role of synovectomy in total knee arthroplasty: a prospective analysis of 30 cases. J. Evolution Med. Dent. Sci. 2016;5(60):4161-4164, DOI: 10.14260/jemds/2016/950

\section{INTRODUCTION}

While osteoarthritis remains the most common indication for total knee replacement, the number of primary total knee arthroplasties performed annually has increased exponentially over the last few decades. Outcomes have improved with the use of careful preoperative assessment, a range of component options, and operative technique guided by clear surgical goals.

A small group of patients are still unhappy in spite of wellplanned and aligned implants. The source of their pain and discomfort is yet to be ascertained. Our observations in this study may give some indication towards the future analysis of this problem. In RA patients, management of synovitis along with TKA has also been a concern. In the presence of active inflammatory synovitis, complete synovectomy is

Financial or Other, Competing Interest: None.

Submission 02-05-2016, Peer Review 08-07-2016,

Acceptance 13-07-2016, Published 26-07-2016.

Corresponding Author:

Dr. Kumar Chandan,

Moossariparambil House,

Kidangaparambu Ward,

Thathampally P. $O$.

Alappuzha-688013,

E-mail: drkumarchandan@gmail.com

DOI: $10.14260 /$ jemds $/ 2016 / 950$ recommended because recurrent synovitis after TKA may occur in this patient group, and complete synovectomy in such patients may lead to improvement in the patient's general condition and lesser usage of analgesics.

Another area of concern is TKR in tuberculous arthritis. J.D. Burger et al $^{1}$ have shown that there is a strong possibility of missing the pathology preoperatively. Also, there is a possibility of missing the histopathology if the specimen is non-representing. Hence, the synovectomy will be therapeutic and diagnostic in such occasions.

Pain following knee arthroplasty can arise from a variety of causes including loosening, infection, component malposition, inadequate soft tissue balancing, arthrofibrosis, and soft tissue impingement. ${ }^{2}$

In the absence of a bleeding disorder, the most common underlying pathology for recurrent haemarthrosis is impingement of the proliferative synovium. ${ }^{3}$

A thorough history and examination together with relevant radiological and laboratory investigations will identify most of the causes.

The aim of our study is to evaluate the role of near total synovectomy in TKA and the functional outcome. There are very few literatures available in support of near total synovectomy considering the rarity of this study. We have conducted a study on the role of near-total synovectomy in all 
case of TKA and we found that it is a very good adjunct to the surgery, which alleviates many synovium-related complications in post TKA patient.

Though, there are many literatures in favour of synovectomy in patient with pigmented villonodular synovitis, rheumatoid arthritis, lipoma arborescens of knee, but the importance of synovectomy in TKA is less evaluated. Our main aim of this study is to get complete pathological diagnosis avoiding postoperative complications originating from the left out synovium in the immediate and late postop period.

\section{MATERIAL AND METHODS}

The material for this study comprised of patients with either primary or secondary OA knee of age between 55-70 years operated at Government T. D. Medical College, Alappuzha, Kerala, India. Detailed clinical and radiological work up done prior to the surgery. Routine investigations to find out any underlying pathology were also performed. Standard TKA done under spinal/epidural anaesthesia. Out of 30 patients, 24 patients had varus knee deformity and rest of the patients had valgus knee deformity, 10 patients was known diabetic, 15 patients was hypertensive on treatment. Out of 30 patients only 3 patients were male.

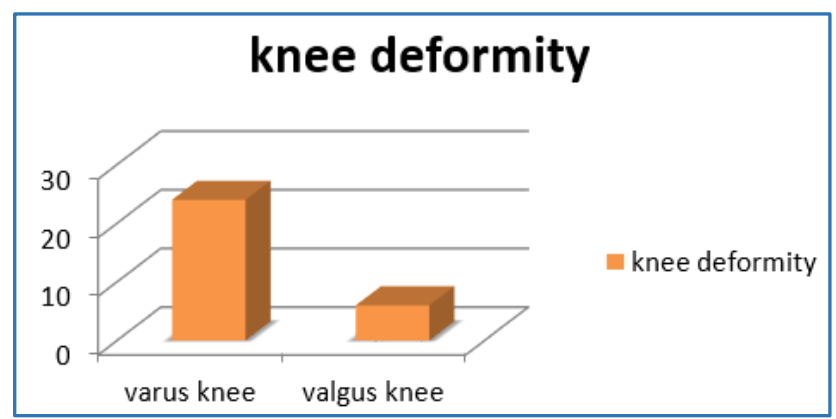

Chart-1

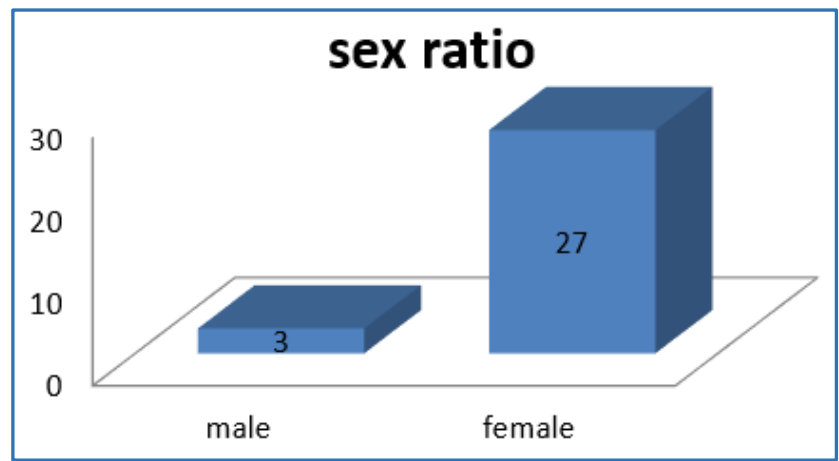

Chart-2

Two patients had previous history of contact or treatment for extraskeletal tuberculosis. Two patients had history and treatment suggestive of rheumatoid arthritis.

All the patients had weight bearing related pain or decrease in range of motion. 12 patients had associated varus thrust while walking, 10 patients had knee joint swelling. The procedure was combined with near-total synovectomy from suprapatellar pouch and medial and lateral parapatellar gutters in all cases and bone grafting was done for one patient with medial tibial plateau defect. Bone grafts for media tibial plateau was harvested for proximal tibia bone cut.

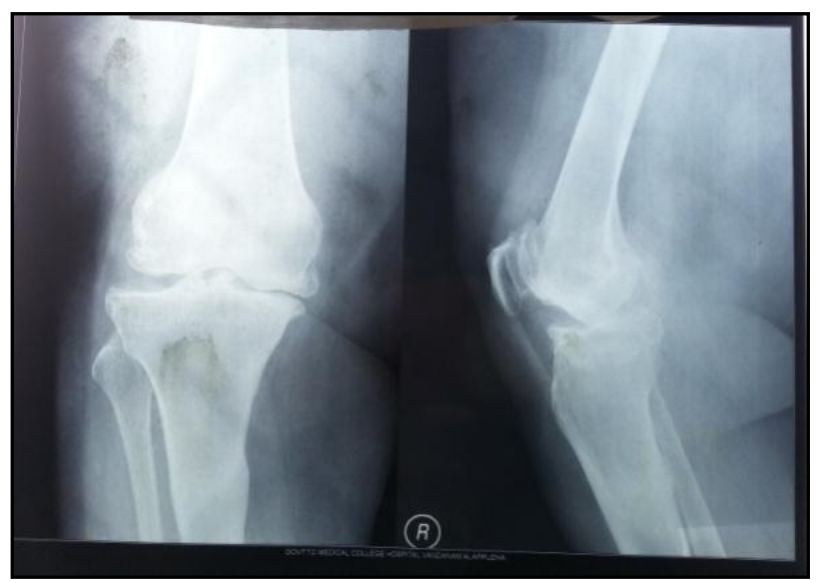

Fig.1: X-Ray Right Knee Showing Gross Osteoarthritis With Varus Deformity of Knee

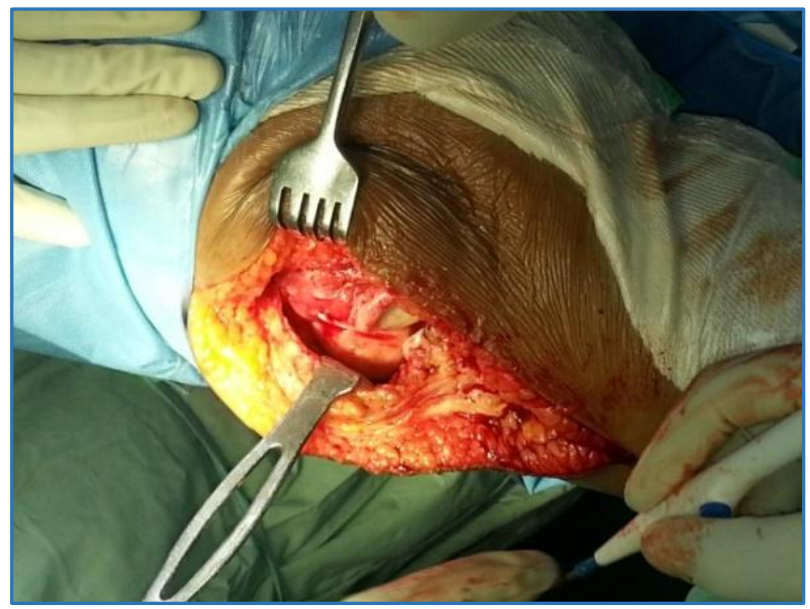

Fig.2: Midline Incision and Medial Parapatellar Approach

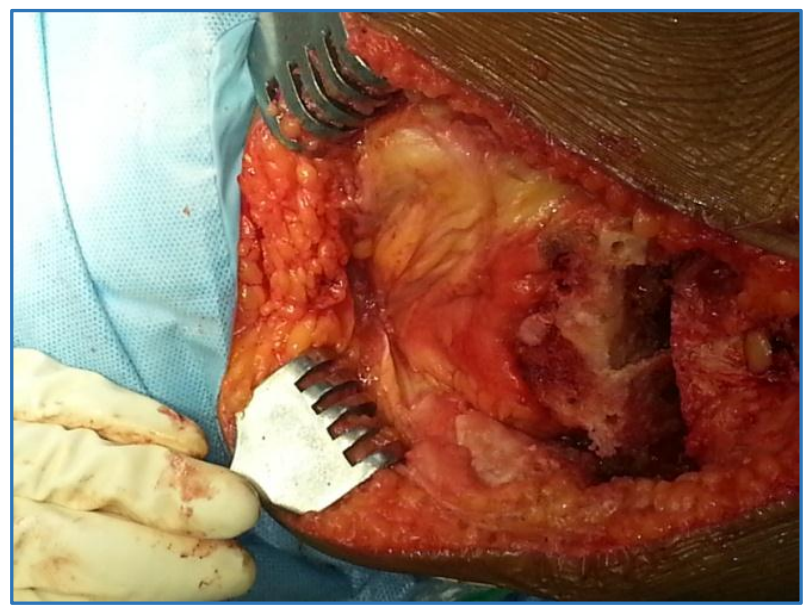

Fig. 3: Suprapatellar Pouch Filled with Hypertrophied Synovium 


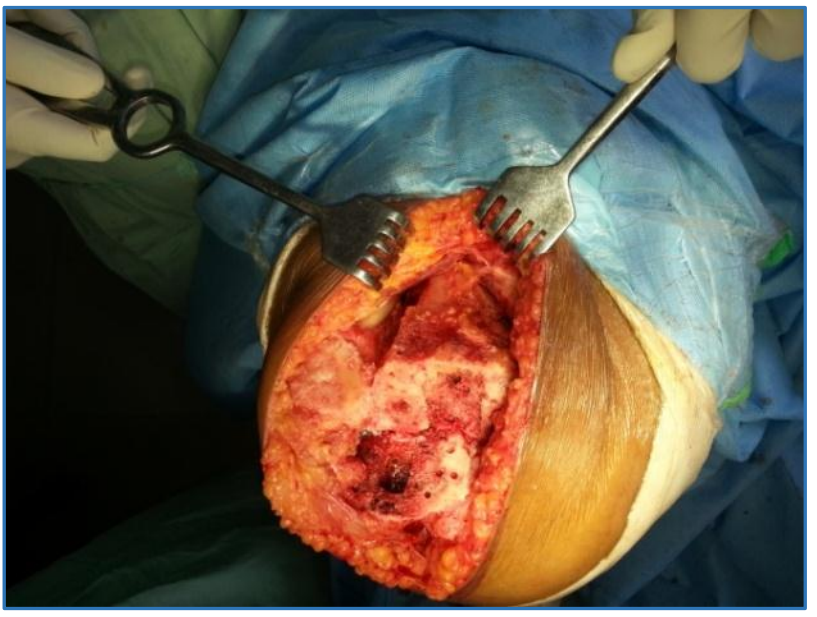

Fig. 4: Suprapatellar Pouch after Synovectomy

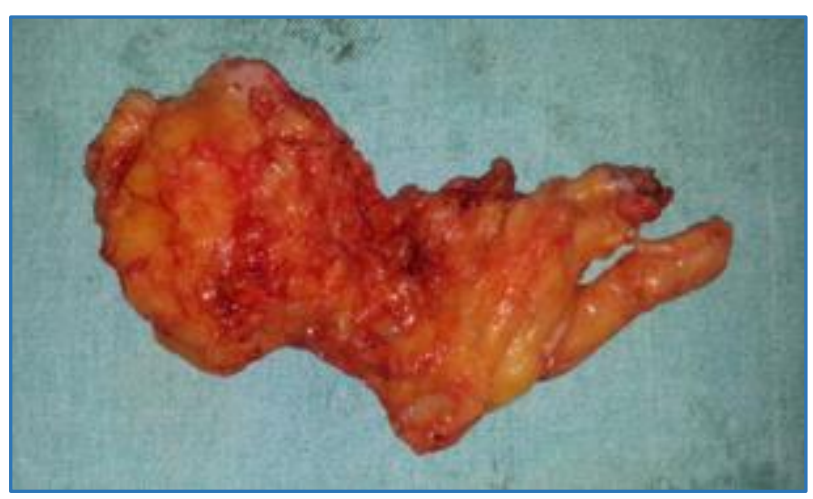

Fig. 5: Near-Total Synovectomy Specimen

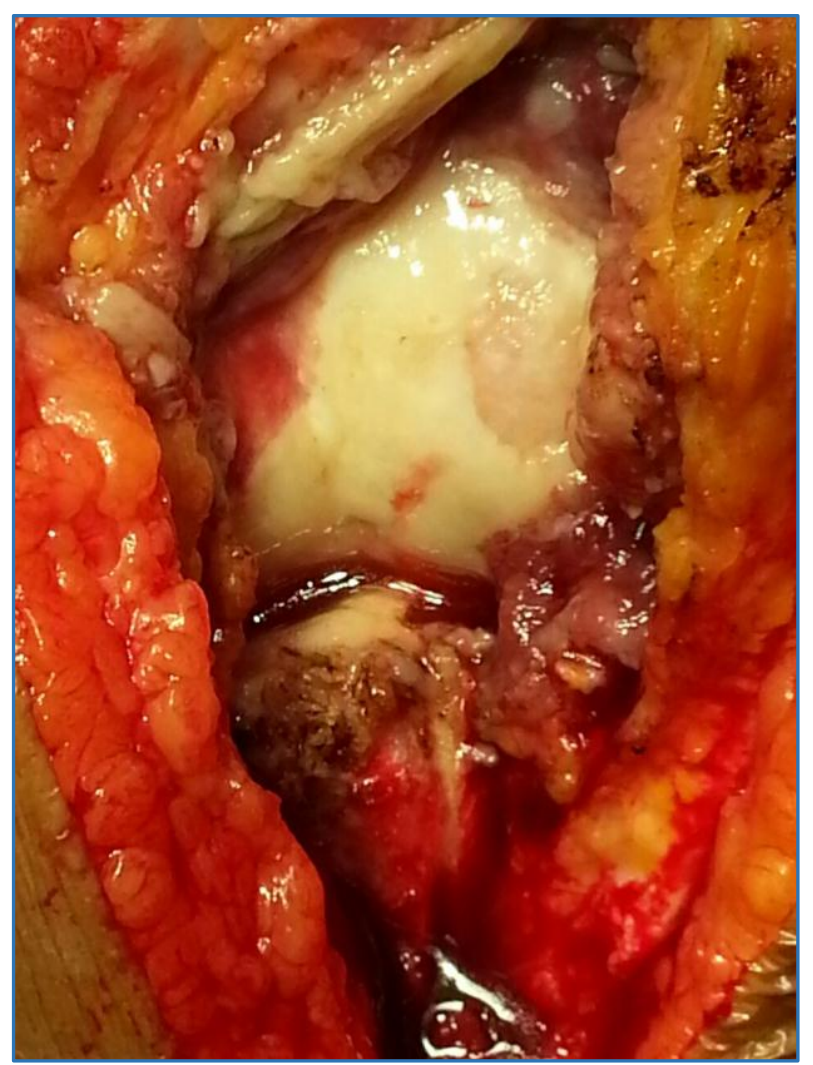

Fig. 6: Granulation and Caseous Material Seen During TKA

Standard postoperative protocol was followed in all cases. Wound inspection was done on the second postoperative day and passive mobilisation of the knee was encouraged as soon as pain alleviated. Patients were started protected weight bearing with walker on $4^{\text {th }}$ postoperative day. CPM started for all patients during postop rehabilitation period.

\section{RESULTS}

Patients were followed up at 1 month, 3 months, 1 year, and yearly once thereafter for a minimum of 3 year. Postoperative suction drain was removed after 48 hours and amount of drain collection was average $200 \mathrm{~mL}$ (Range 150-220 mL). Outcome was measured using the Lysholm knee scoring scale and the average score was 80.5 .

17 knees were scored as excellent 10 as good and 3 as fair. All the patients improved symptomatically following the procedure. During each postop visit, knee swelling were observed and it was found in our study that none of the patients hand knee swelling after total knee arthroplasty. In our study, mean range of movement obtained was 115 degrees with range from 100 to 120 degrees.

\section{DISCUSSION}

Pain following knee arthroplasty can arise from a variety of causes including loosening, infection, component malposition, inadequate soft tissue balancing, arthrofibrosis, recurrent effusion, and soft tissue impingement. A thorough history and examination together with relevant radiological and laboratory investigations will identify most of the causes ${ }^{4}$ There have been previous reports of soft tissue impingement in the intercondylar notch and impingement or tethering in the patellofemoral joint causing pain following TKR. Fabellar impingement is also a rare cause of such pain. This case demonstrates a specific location and cause of pain due to soft tissue impingement following TKR which to our knowledge has not been previously reported. 4

Patellar clunk syndrome was described by Thomas J. Heyse $^{5}$ is a painful condition associated with a mechanical catching or clunking during active extension following Total Knee Arthroplasty (TKA). The syndrome is caused by growth of interposing soft tissue usually at the superior pole of the patella. In our series, no patellar clunk noticed after TKA.

David C. Pollock et al ${ }^{6}$ study shows synovial entrapment is characterised by hypertrophic synovial tissue at the superior pole of the patella. Use of a posterior stabilised femoral component with a proximally positioned or wide femoral box is more likely to result in this complication. In our study, there was no such observation found.

Fibrous nodule forms on the posterior surface of the quadriceps tendon just above the superior pole of the patella can become entrapped in the intercondylar notch of the femoral prosthesis and cause the knee to pop or "clunk" at 30 to 45 degrees of knee flexion as the knee is actively extended, which can be better avoided by near-total synovectomy. The recommended treatment for this condition is arthroscopic debridement of the nodule.

In our study, we found one case of PVNS in histopathology analysis of synovectomy specimen. Chung et $\mathrm{al}^{7}$ and Brian R. Hamlin et al $^{8}$ have reported cases of the failures due to aseptic loosening and recurrence of the disease in case of PVNS. 


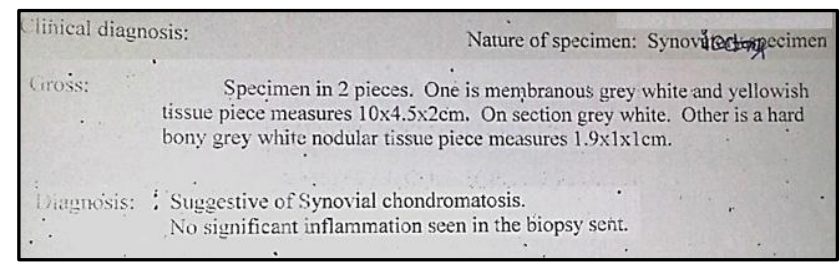

Fig. 7: Histopathology Report of Synovectomy Showing Chondromatosis

\begin{tabular}{|c|c|c|}
\hline Pathology & No. of Cases & $\mathbf{\%}$ \\
\hline Non-specific synovitis & 22 & 73.3 \\
\hline Rheumatoid synovitis & 3 & 10 \\
\hline Tuberculous synovitis & 3 & 10 \\
\hline PVNS & 1 & 3.3 \\
\hline Synovial chondromatosis & 1 & 3.3 \\
\hline Others & 0 & 0 \\
\hline \multicolumn{2}{|c|}{ Table 1: Histopathology Data } \\
\hline
\end{tabular}

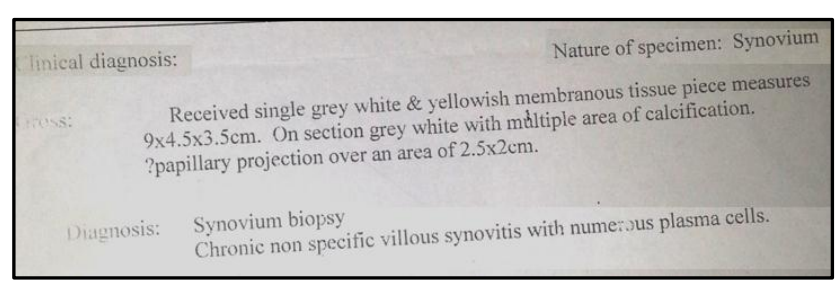

Fig. 8: Histopathology of Synovectomy Specimen Showing Chronic Nonspecific Villous Synovitis

In Mannucci $\mathrm{PM}$ et $\mathrm{al}^{3}$ study, they performed total synovectomy in all patients and they found that in the majority of cases (53\%), there was no recurrence of haemarthrosis; in the others, the condition was reduced $(40 \%)$ or unchanged (7\%).

In A. D. Toms et al ${ }^{9}$ study, the most common underlying pathology for recurrent haemarthrosis is impingement of the proliferative synovium. In our study as we routinely performed near-total synovectomy, there was no case of recurrent haemarthrosis or effusion after TKA stressing the fact that in a well-executed knee replacement surgery, synovium is the source of pain and disability especially if pathological and left behind.

R. J. Spinner et $\mathrm{al}^{10}$ and Ramesh Vyravan et al ${ }^{11}$ have stressed that though TKA is not contraindicated in the presence of active tuberculosis, due absence of a true biofilm formation, a missed or delayed diagnosis often lead to catastrophic complications like periprosthetic infection, sinus formation, secondary infection often leading to revision. In our series, we could remove 3 cases of tuberculous synovium.

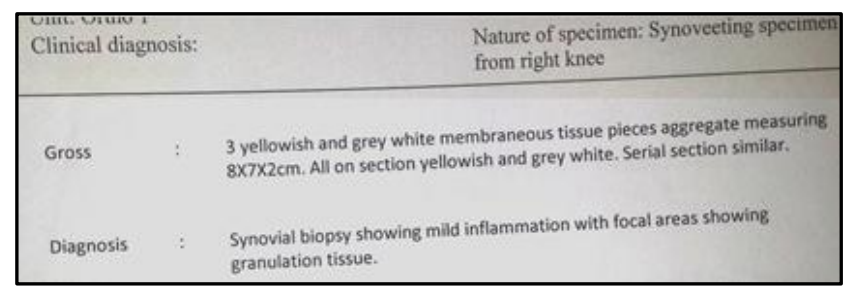

Fig. 9: Histopathology Report Showing Tuberculous Synovitis

Component loosening and revision arthroplasty have been reported following a specific, but less reported condition called "metal-induced synovitis"12. By performing a near-total synovectomy, this complication maybe reduced or avoided.
In our study, we found 3 cases of rheumatoid arthritis, which was confirmed by histopathological report and our study was comparable with Jin Kyu Lee et $\mathrm{al}^{2}$ study.

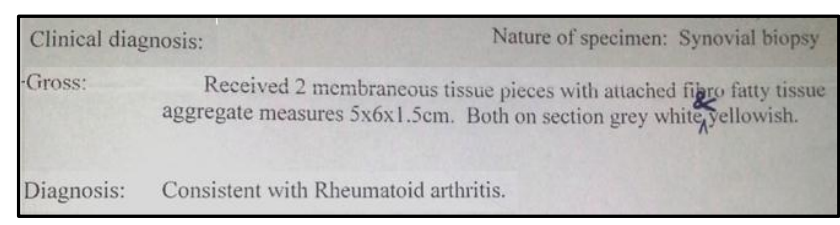

Fig. 10: Histopathology of Synovectomy Specimen Showing Rheumatoid Arthritis

\section{CONCLUSION}

Performing synovectomy in TKA will give complete pathological diagnosis avoiding persistence of synovial pathology along with long-term benefits of synovectomy like no joint effusion, less pain, no synovial hypertrophy, and good range of movement of knee.

Role of synovium in producing complications and unsatisfactory outcome in a well-performed TKA must be evaluated further taking clues from this pilot study.

\section{REFRENCES}

1. Burger JD, de Jongh H. TKR infected with mycobacterium tuberculosis: a case study and review of the literature. South African Orthopaedic Journal 2013;12(2).

2. Lee JK, Choi $\mathrm{CH}$. Total knee arthroplasty in rheumatoid arthritis. Knee Surg Relat Res 2012;24(1):1-6.

3. Mannucci PM, De Franchis R, Torri G, et al. Role of synovectomy in haemophilic arthropathy. Israel J Med Sci 1977;13(10):983-7.

4. Barr L, Khanduja V, Owen J. An unusual cause of lateral knee pain following total knee replacement. Hindawi Publishing Corporation. Case reports in orthopaedics Article ID 569413, 2011;2011:3.

5. Heyse TJ, Chong LR, Davis J. MRI diagnosis of patellar clunk syndrome following total knee arthroplasty. HSS J 2012;8(2):92-5.

6. Pollock DC, Ammeen DJ, Engh GA. Synovial entrapment: a complication of posterior stabilised total knee arthroplasty. J Bone Joint Surg Am 2002;84-A(12):2174-8.

7. Chung BJ, Park YB. Pigmented villonodular synovitis after TKA associated with tibial component loosening. Orthopaedics 2011;34(8):e418-20.

8. Hamlin BR, Duffy GP, Trousdale RT, et al. Total knee arthroplasty in patients who have pigmented villonodular synovitis. J Bone Joint Surg Am 1998;80(1):76-82.

9. Toms AD, Mandalia V, Haigh R. The management of patients with painful total knee replacement. J Bone Joint Surg Br 2009;91(2):143-50.

10. Spinner RJ, Sexton DJ, Goldner RD, et al. Periprosthetic infection due to mycobacterium tuberculosis in patients with no prior history of tuberculosis. The Journal of Arthroplasty 1996;11(2):217-22.

11. Vyravan PR, Choudhary BM, Kumar MM. Total knee replacement in tuberculous arthritis-reporting an unsuspected case. ISOR Journal of Dental and Medical Sciences 2014;13(8):11-3.

12. Jason W, Romesburg. Metal-induced synovitis and metallosis after TKA: review of radiographic and CT findings. J Radiology Case Report 2010;4(9):7-17. 